\title{
Differential treatment of intentional and accidental violators
}

\author{
Thomas Blondiau $^{\mathrm{a}}$ and Sandra Rousseau ${ }^{\mathrm{b}}$ \\ ${ }^{a}$ CES, K.U. Leuven, Naamsestraat 69, B-3000 Leuven, Belgium, \\ E-mail: Thomas.Blondiau@econ.kuleuven.be \\ b FEM, HUBrussel, Stormstraat 2, B-1000 Brussel, Belgium, \\ \& CES, K.U. Leuven, Naamsestraat 69, B-3000 Leuven, Belgium, \\ E-mail: Sandra.Rousseau@econ.kuleuven.be
}

\begin{abstract}
We investigate whether environmental sanctions should increase with the degree of intentionality of the violation. To this end we develop a simple model which is used to make predictions concerning the effect of the degree of intentionality, the amount of illegal gain obtained and the harm caused by the offense on the level of the optimal fine. These predictions are then used to learn more about the objectives pursued by enforcing authorities. We empirically test our theoretical predictions for firms as well as individuals using data on criminal environmental sanctions in Flanders and administrative environmental fines in Brussels. We find that judges and administrative officers aim at a mixture of social welfare maximization and regulation compliance maximization. Also, we find that in practice intentionality of a violation is always a factor which makes the sanction level increase. This is in contrast to a result from our theoretical analysis, in which we demonstrate that more intentional violations can lead to lower optimal fines.
\end{abstract}

Keywords: Enforcement; Criminal and administrative penalties; Environmental crime 


\section{Introduction}

In practice, environmental violations can be the result of accidental circumstances but also of intentional actions by one or more parties involved. Thus, offenses can be characterized by their degree of intentionality. Based on the degree of intentionality or willfulness of an environmental violation, we can divide offenses into four broad categories (see DEP 2002): 1) accidental violations defined as violations beyond the control of the violator; 2) negligent violations caused by a failure to prevent occurrence or correct a violation due to indifference, lack of reasonable care, or lack of diligence; 3) reckless violations caused by a conscious disregard or indifference to the consequences of their actions, with full knowledge, however, the act was not intentional; and 4) deliberate or willful violations caused by an intentional action or intentional lack of action.

Previous studies often find different sanctions for intentional versus accidental violations in judicial or administrative guidelines concerning environmental sanctions (see e.g. DEP 2002). Shavell (1985) theoretically argues that intent should lead to higher penalties in criminal cases because it is likely to be correlated with harm, with gain and with avoidance efforts. Moreover, in empirical studies intent-related factors significantly mattered as a recent literature survey of determinants of environmental sanctions by Rousseau (2009) shows. Several studies (e.g. Earnhart 1997, Kleit et al. 1998) incorporate variables relating to the cause of the offense. When the cause was related to human influence or negligence, the penalty imposed was significantly higher. Also, when the offense was labeled as being intentional, the penalty increased significantly (Rousseau and Billiet 2005). Thus, in practice intentional violations seem to be punished harsher than accidental ones.

In order to study the effect of intentionality on environmental sanctioning, we make an explicit link with firms' risk exposure. The day-by-day decisions of firms generally involve certain risks. Firms can never be absolutely certain that their production processes will not lead to damage to public health and/or the environment. After all, machines and abatement equipment can break down, communication concerning managerial decisions can be misinterpreted and employees can be inattentive or insufficiently trained. However, firms can limit these risks by taking preventive actions 
and limit the damages by taking fast measures. Thus, we can distinguish between voluntary and involuntary risk exposure by firms. The degree of voluntary risk exposure is also referred to as the willfulness or the intentionality of an environmental violation.

First, we investigate whether environmental sanctions should increase with the degree of intentionality of the violation in theory. To this end we develop a simple model which is then used to make predictions concerning the effect of the degree of intentionality, the amount of illegal gain obtained and the harm caused by the offense on the level of the optimal fine. Moreover, these predictions can be used to learn more about the objectives pursued by enforcing authorities. Recently, Blondiau and Rousseau (2010) analyze the criminal judges' objective function in Flanders by focusing on the choice between monetary and non-monetary sanctions for environmental violations of firms. They find that besides minimizing environmental damages judges also take social costs of sanctions into account in their decision-making. Firestone (2002) investigated six possible objective functions of the US Environmental Protection Agency (EPA) using an empirical analysis of administrative sanctioning decisions and he found empirical support for social welfare maximization and for environmental harm minimization as objectives pursued by the US EPA. Heyes and Kapur (2009) develop a theoretical model to analyze whether target-driven or budget-driven objectives provide the most cost-effective deterrence incentives. They find that target-driven objectives are always preferable over budget-driven objectives for an environmental enforcement agency, because they provide more cost-effective enforcement incentives. The authors exploit positive spillover effects when different regulated firms need to make simultaneous compliance decisions to get to this result. Also, Rousseau (2009) concludes that the social welfare maximization objective implies a harm-based approach to environmental enforcement, while maximizing deterrence leads to a gain-based approach.

In the next step, we investigate whether in practice intentional violators are punished more severely than accidental violators. Therefore, we empirically test our theoretical predictions for firms as well as individuals using data on criminal environmental sanctions in Flanders and administrative environmental fines in Brussels. We find that judges and administrative officers aim at a mixture of social welfare maximization and regulation compliance maximization. Also, in practice it seems that the degree of 
intentionality of a violation always makes the sanction level increase. This is in contrast to a result from our theoretical analysis, in which we show that optimal fines could be lower for more intentional violations.

In the next section we use a simple theoretical model to develop predictions to be tested in an empirical setting. In section III, we present our data for the empirical analysis. We describe our estimation results in section IV and discuss them in section V. Section VI ends with a general conclusion.

\section{Model}

Firms and individuals make compliance decisions. Depending on the action selected, firms, individuals and environment face more or less risks. We explicitly distinguish between voluntary and involuntary risk exposure. Voluntary risk exposure is the result of conscious choices made by economic agents, while involuntary risk exposure is independent of the decisions made. A prudent firm or individual, for instance, will run a small risk of an incident and of implementing harm to the environment, while a reckless agent will run a high risk of an incident occurring. When the level of voluntary risk

exposure is represented by $\alpha_{i} \in[0,1]$, the probability $p_{\text {inc }}\left(\alpha_{i}\right)$ that an incident occurs is defined as:

$$
p_{\text {inc }}\left(\alpha_{i}\right)=\left\{\begin{array}{cl}
\varepsilon & \text { if } \alpha_{i}=0 \\
\varepsilon+\alpha_{i}[1-\varepsilon] & \text { if } 0<\alpha_{i}<1 \\
1 & \text { if } \alpha_{i}=1
\end{array}\right.
$$

The involuntary risk of causing an environmental incident by a prudent firm or individual is then denoted by $\varepsilon>0$. The involuntary risk faced by the decision maker includes incidents caused by mechanical failure, extreme weather conditions (e.g. storm or floods) or actions by third parties. Agents can never be absolutely certain that their actions will not damage public health or the environment. Thus, incidents concerning firms or individuals that face only involuntary risks $\left(\alpha_{i}=0\right)$ are the result of accidental violations. Incidents concerning agents that have a degree of voluntary risk exposure 
equal to one $\left(\alpha_{i}=1\right)$ are then resulting from deliberate or willful violations. In general, we assume that the environmental harm $h$ associated with an incident is independent of the risk level selected by the firm and that the prosecution of an offender costs an amount $k$ to society (e.g. prosecution and court costs and administrative costs). The concept of voluntary risk exposure is thus similar in flavor as the legal concept of dolus generalis or 'general intent' that is used in (Belgian) criminal law (Van den Wyngaert, 2006). Intent is defined in Belgian criminal law as 'the purposeful intention to perform an act (or to keep from performing an act) that is prohibited by law' (Van den Wyngaert, 2006).

We assume that the regulator requires all firms and individuals to avoid exposure to voluntary environmental risks; i.e. $\alpha$ should be zero for all agents ${ }^{1}$. This implies a type of negligence rule where agents are expected to take a sufficient amount of care to avoid voluntary risk exposure. However, the degree of risk exposure is private information and the regulator has to inspect firms and individuals in order to determine $\alpha$. Moreover, the number of inspections that the regulator can perform is limited due to budgetary restrictions and thus only a proportion of agents are inspected each year. Assuming that compliance costs differ across agents, not all firms and individuals will have a sufficient incentive to comply with the environmental regulation.

\subsection{Agent behavior}

Economic agents decide on the level of risk exposure $\alpha_{i} \in[0,1]$ such that their costs are minimized. However, firms and individuals can also try to avoid detection (see e.g. Malik 1990, Sanchirico 2006 and Langlais 2008). The level of avoidance activity is represented by $\beta_{i} \in[0,1]$ where $\beta_{i}=0$ implies no avoidance effort and $\beta_{i}=1$ implies perfect avoidance. The total costs $T C_{i}$ incurred by agent $i$ are defined as the sum of compliance costs $C_{i}\left(\alpha_{i}\right)$, the avoidance costs $A\left(\beta_{i}\right)$ and the expected fine, i.e. probability of prosecution $p_{i}$ times the imposed fine $F_{i}$ :

$$
\min _{\alpha_{i}} T C_{i}=\min \left[C_{i}\left(\alpha_{i}\right)+A\left(\beta_{i}\right)+p\left(\alpha_{i}, \beta_{i}\right) F\left(\alpha_{i}, \beta_{i}\right)\right]
$$

\footnotetext{
${ }^{1}$ This is obviously a normalisation to simplify the model. The threshold between voluntary and involuntary risk exposure can - at least to some extent - be chosen by the regulator.
} 
Compliance costs are a negative function of risk exposure $\alpha$, avoidance costs are a positive function of avoidance effort $\beta$, while the probability of prosecution is a positive function of $\alpha$ and a negative function of $\beta\left(\frac{\partial p}{\partial \alpha}>0 ; \frac{\partial p}{\partial \beta}<0\right)$. The probability of prosecution is equal to:

$$
p\left(\alpha_{i}, \beta_{i}\right)=\left[1-p_{\text {inc }}\left(\alpha_{i}\right)\right] \bar{p}+p_{\text {inc }}\left(\alpha_{i}\right)\left[1-\beta_{i}[1-\bar{p}]\right]
$$

where $\bar{p}$ represents the exogenous random inspection frequency with which the inspection agency inspects economic agents when no incident occurred or when it seems as if no incident occurred. The full derivative of the probability of detection with respect to $\alpha$ can be positive or negative depending on the relative size of the prosecution costs and the marginal avoidance costs: $\frac{d p}{d \alpha}>0$ if $p_{\text {inc }}\left(\alpha_{i}\right)[1-\bar{p}] \frac{k}{A^{\prime}}<1-\beta_{i}$. When the marginal avoidance costs are considerably larger than the prosecution costs, the impact of increasing the risk exposure increases the optimal probability of detection even when taking avoidance into account.

As we will show, the impact of the selected degree of risk on the fine imposed by the enforcing authorities depends on the specific case we will be considering. Also, we will show that the level of the optimal fine will be increasing in the level of avoidance effort.

The optimal level of avoidance $\beta_{i}^{*}$ for each level of risk exposure is determined by the following conditions:

$$
\begin{array}{lr}
\beta_{i}^{*}=0 & \text { if } \alpha_{i}=0 \\
\frac{d A\left(\beta_{i}^{*}\right)}{d \beta}=p_{\text {inc }}\left(\alpha_{i}\right)[1-\bar{p}] F\left(\alpha_{i}, \beta_{i}^{*}\right)-p\left(\alpha_{i}, \beta_{i}^{*}\right) \frac{d F\left(\alpha_{i}, \beta_{i}^{*}\right)}{d \beta} & \text { if } \alpha_{i}>0
\end{array}
$$

For an interior solution, the marginal increase in avoidance costs equals the marginal decrease in the expected fine associated with the increase in avoidance efforts. The first term is always positive, i.e. the increase in avoidance efforts leads to a decrease in the probability of prosecution. The sign of second term is ambiguous. From this expression, we can also see that optimal avoidance effort $\beta_{i}$ is increasing in the level of voluntary risk exposure $\alpha_{i}$. 
The degree of risk exposure $\alpha_{i}$ selected, given the optimal level of avoidance $\beta_{i}^{*}$, is then determined by the following expression:

$$
-\frac{d C\left(\alpha_{i}\right)}{d \alpha}=\frac{d p\left(\alpha_{i}, \beta_{i}^{*}\right)}{d \alpha} F\left(\alpha_{i}, \beta_{i}^{*}\right)+p\left(\alpha_{i}, \beta_{i}^{*}\right) \frac{d F\left(\alpha_{i}, \beta_{i}^{*}\right)}{d \alpha}
$$

Thus, we obtain the standard result that - for an interior solution - the savings in compliance costs due to marginally increasing the size of the violation should be equal to the increase in the marginal expected sanction. When the marginal compliance costs at the level $\alpha_{i}=0$ are lower than the marginal expected sanction at that point, economic agents will perfectly comply with the regulation and only involuntary risks will be run. Hence, the higher the marginal compliance costs and/or the lower the marginal expected fine, the higher the degree of voluntary exposure selected by the economic agents.

\subsection{Enforcing authority}

We distinguish two possible and commonly used objective functions for the enforcement authority: i) maximization of social welfare and ii) maximization of deterrence or compliance. A more detailed discussion of the objective functions used by environmental monitoring and enforcement authorities can be found in Heyes and Kapur (2009), Firestone (2002) and Rousseau (2009). Based on an overview of the literature, Rousseau (2009) concludes that the social welfare maximization objective implies a harm-based approach to environmental enforcement, while maximizing deterrence leads to a gainbased approach. Furthermore, we make a distinction between cases where actual harm occurred following an incident (case 1) and cases where no harm occurred but the positive risk of harm occurring was present (case 2). Next we discuss both cases in more detail.

\section{Case 1: Harm occurred}

In this case, the probability of prosecution equals $p\left(\alpha_{i}, \beta_{i}\right)=p_{\text {inc }}\left(\alpha_{\mathrm{i}}\right)\left[1-\beta_{\mathrm{i}}[1-\bar{p}]\right]$, implying that each incident can be proven to be caused by one particular offender if that particular offender does not invest in avoidance ${ }^{2}$.

\footnotetext{
${ }^{2}$ Again, this normalization does not change the main insights from the model.
} 
Firstly, we discuss an enforcing authority who aims at maximizing social welfare. Hence, the imposed sanctions are based on compensatory damages to force economic agents to take external costs (i.e. environmental harm) into account. As shown by among others Polinsky and Shavell (1994), the optimal fine is based on the harm caused. The optimal harm-based fine then equals (Polinsky and Shavell 2000) ${ }^{3}$ :

$$
F_{H i}^{*}=\frac{h}{p\left(\alpha_{i}, \beta_{i}\right)}+k
$$

Thus, if the level of risk exposure chosen by the offender increases, the penalty imposed by the enforcing authorities for a given level of harm can be either increasing or decreasing depending on the relative size of the prosecution and marginal avoidance costs. When the marginal avoidance costs are sufficiently larger than the fixed prosecution costs, optimal sanctions are decreasing with higher intentionality (due to the higher detection probabilities $)^{4}$.

Secondly, we assume that the enforcing authority aims at maximizing compliance. The leading principles include the notion that rules should be obeyed and that crime should not be profitable. As is shown in the literature (see e.g. Cohen 1999) this implies that environmental sanctions should by based on the size of the gain obtained by the violation. The optimal gain-based fine now equals:

$$
F_{G i}^{*}=\frac{C_{i}(0)-C_{i}\left(\alpha_{i}\right)}{p\left(\alpha_{i}, \beta_{i}\right)}+k
$$

This implies that the optimal gain-based fine is independent of the size of the environmental harm caused and depends positively on the amount of compliance costs saved by the offender and on the level of avoidance activity. The effect of the level of voluntary risk exposure is ambiguous.

\section{Case 2: No harm occurred}

\footnotetext{
${ }^{3}$ The optimal sanction is bounded upwards because we assume that sanctions are costly given risk-averse (and liquidity constrained) agents. We have shown in a previous paper (Blondiau \& Rousseau, 2010) that judges in Belgium do take these costs into account.

${ }^{4}$ Note that expected sanctions, however, are still increasing with voluntary risk exposure.
} 
In this case, the probability of prosecution equals the probability of detection which is assumed to be independent of risk behavior: $p\left(\alpha_{i}, \beta_{i}\right)=\bar{p}$. Since no incident occurred (yet) but agents still displayed risky behavior, this type of sanction is called risk-based or act-based sanctions (Shavell, 1993). As outlined by Innes (2004), this type of regulation may be preferred in case of serious environmental hazards. Garoupa and Obidzinski (2006) state that enforcement of risk-based cases should in general be less stringent in terms of sanctioning levels and number of prosecution cases compared to harm-based cases.

Firstly, we again assume that the enforcing authority maximizes social welfare. The optimal risk-based fine then equals:

$$
\begin{array}{ll}
F_{R i}^{*}=0 & \text { if } \alpha_{i}=0 \\
F_{R i}^{*}=\frac{p_{\text {inc }}\left(\alpha_{i}\right) h}{\bar{p}}+k & \text { if } \alpha_{i}>0
\end{array}
$$

Thus, the optimal fine is now increasing in the level of risk exposure for a given level of potential harm. The expected fine $\bar{p} \times F_{i}^{*}\left(\alpha_{i}\right)$ is also increasing in $\alpha$.

Secondly, we assume that the enforcing authority maximizes compliance. The optimal gain-based fine now equals:

$$
\begin{array}{ll}
F_{G i}^{*}=0 & \text { if } \alpha_{i}=0 \\
F_{G i}^{*}=\frac{C_{i}(0)-C_{i}\left(\alpha_{i}\right)}{\bar{p}}+k & \text { if } \alpha_{i}>0
\end{array}
$$

This again implies that the optimal gain-based fine is independent of the size of the environmental harm caused and dependent on the amount of compliance costs saved by the offender. Furthermore, the fine is increasing in the level of voluntary risk exposure when no actual harm occurred.

\subsection{Discussion}

Depending on the occurrence of harm and the objective functions of the enforcing authorities, we can make several testable predictions concerning the influence of the degree of voluntary risk selected by the offender, the size of the benefits or gain resulting from the offense and the (potential) harm caused by the offense on the level of the 
imposed fine (see table 1). Thus the reaction of enforcing authorities to the intentionality, profitability and harmfulness of the violation reveals something about the objectives pursued by these authorities. Depending on which of these relations hold, we investigate in the following section which objectives influence environmental sanctioning decisions by criminal and administrative enforcement authorities in Flanders and Brussels.

\begin{tabular}{|l|c|c|c|c|}
\hline \multirow{2}{*}{} & \multicolumn{2}{|c|}{ Harm occurred } & \multicolumn{2}{c|}{ No harm occurred } \\
\cline { 2 - 5 } & $\begin{array}{c}\text { Welfare } \\
\text { Max }\end{array}$ & $\begin{array}{c}\text { Compliance } \\
\text { Max }\end{array}$ & $\begin{array}{c}\text { Welfare } \\
\text { Max }\end{array}$ & $\begin{array}{c}\text { Compliance } \\
\text { Max }\end{array}$ \\
\hline $\begin{array}{l}\text { Voluntary risk exposure } \\
\text { (intent) increases }\end{array}$ & $?$ & $?$ & Increase & Increase \\
\hline Gain increases & Constant & Increase & Constant & Increase \\
\hline Harm increases & Increase & Constant & Increase & Constant \\
\hline
\end{tabular}

Table 1: Impact of intent, gain and harm on different types of fines

Previous empirical studies (see overview in Rousseau 2009) show a positive and statistically significant relation between intent-related factors and the level of the penalty. Intent-related factors include variables indicating the cause of the offense: when the cause was related to human influence or negligence the penalty imposed was significantly higher than for cases that involved accidental factors or technical failures. The empirical analyses performed so far do not allow us to establish whether gain-related factors influence the level of monetary fines. Looking at harm-related variables, we see that penalty amounts routinely increase with the seriousness of the violation. Penalties were found to increase, for example, with the number of violations, with the amount of measured damages, or with the presence of third parties that were harmed by the offense. Also, remedial actions taken by the violator in order to limit harm, were found to lower penalties. 


\section{Data}

First, we describe the dataset we are using and next we look at the dependent and explanatory variables that are included in the estimation of the sanction level.

\subsection{Dataset}

The database contains information on criminal sanctions as well as administrative sanctions for environmental violations. The criminal sanctions are imposed by the Courts of First Instance in seven judicial districts of the Flemish region in Belgium ${ }^{5}$. In total, we dispose of 1313 first instance judgments being made between 2003 and 2006. The administrative sanctions are imposed by the Brussels Environmental Agency (BIM). We dispose of 610 fining decisions that were imposed between 2004 and 2006.

In this dataset, we distinguish between 'harm' cases and 'no harm' cases. These groups correspond to defendants that really caused a certain environmental harm and defendants who face accusations of displaying risky behavior or causing environmental hazards. For making the distinction between the two cases, we base ourselves on indications related to the type of contamination. A significant share of the offenses carried the indication that 'no contamination was caused'. Thus, the motivation of the sanctions imposed on these defendants cannot be based on real environmental harm estimates. Most of the cases with no contamination recorded involved offenses in which a defendant did not fulfill a legal requirement such as filing for an environmental permit. An alternative group of 'noharm' cases are the cases dealing with noise nuisance where the rationale for deterrence is the possibility that (repeated) exposure to loud music/noise may cause hearing damage. The remaining group of defendants, for whom there was an indication that their violations resulted in environmental harm, are categorized as 'harm' cases. For the group of defendants that face both 'harm' and 'no-harm' offenses, we assume that the offenses leading to actual environmental harm are the most important for determining the level of the sanction. Therefore, we categorize these defendants among the 'harm' group.

\begin{tabular}{|l|l|l|}
\hline Number of defendants in each subset & Harm & No harm \\
\hline
\end{tabular}

\footnotetext{
${ }^{5}$ More information on the design of the database can be found in Billiet et al. (2009).
} 


\begin{tabular}{|l|c|c|}
\hline Criminal track & 1048 & 265 \\
\hline Administrative track & 276 & 334 \\
\hline
\end{tabular}

Table 2: Number of defendants in each subset

As is shown in table 2, the share of 'no harm' cases is much lower in the criminal than in the administrative enforcement track, which is in accordance with the statement of Garoupa \& Obidzinski (2006) that criminal sanctions are more likely to be harm-based and administrative ones are more often risk-based.

\subsection{Dependent variables}

We now outline the construction of the dependent variables to measure the stringency of the sanction in the criminal and the administrative track. For the criminal sanctions, we focus on the main penalties, which are fines and imprisonment sentences, plus the amount of removal of illicit gain awarded. Each sanction imposed consists of an 'effective' component and a 'conditional' component. We believe that the effective sanction is the most appropriate measure of sanction stringency for a certain violation, because the other component is rather used for deterring future offenses. Therefore, we restrict our attention to the effective component of the sanction. Also, we only include proven accusations in our analysis, because the cases where no sufficient proof is available automatically lead to acquittals. It would not make sense to include these observations in our analysis, because in these cases the judge is devoid of all discretionary power. Some descriptive statistics on the main penalties can be found in Table 3.

\begin{tabular}{|l|c|c|c|c|c|}
\hline Variable & $\begin{array}{c}\text { Number of } \\
\text { observations }\end{array}$ & Average & Median & Maximum & Minimum \\
\hline Fine (in $€$ ) & 991 & 4807 & 1000 & 475000 & 55 \\
\hline $\begin{array}{l}\text { Imprisonment } \\
\text { (in months) }\end{array}$ & 33 & 5,4 & 3 & 24 & 1 \\
\hline
\end{tabular}




\begin{tabular}{|l|l|l|l|l|l|}
\hline $\begin{array}{l}\text { Removal of illicit } \\
\text { gain (in } € \text { ) }\end{array}$ & 64 & 403841 & 12701 & 24212597 & 500 \\
\hline
\end{tabular}

Table 3: Descriptive statistics for effective criminal sanctions imposed

Note that the distribution of the fine amounts is skewed to the right, which is reflected in the fact that its average value is significantly higher than the median. The same holds for the requested removal of illicit gain by the public prosecutors. In order to perform a consistent empirical estimation, we construct one value (CRISANC) to indicate the stringency of the sanction which is based on the three components of Table 3. Therefore, we need to find an equivalent monetary value for a jail sentence. To this end, we compare the legal maximum of the fines and imprisonment sentences that can be imposed on natural bodies with the maximum fines for legal entities included in a relevant set of environmental regulations. Since firms cannot be imprisoned, fines for legal entities are higher than those for natural bodies who also face prison sentences. Comparing these differences in maximum fines, we derive an (approximate) equivalent monetary value for prison sentences. For a more detailed explanation, we refer to Appendix 1. Thus, the variable LN(CRISANC) represents the logarithmic transformation of the level of the effective sanction defined as the sum of the monetary equivalent of an imposed prison sentence, the effective fine and the awarded removal of illicit gain. In our dataset (Billiet et al. 2009), judges of the courts of first instance convict three in four defendants. Moreover, one in eight defendants are acquitted, while the remaining defendants without a conviction receive a suspension of the verdict.

For the administrative cases, the dependent variable is equal to the imposed fine (ADMSANC). The variable LN(ADMSANC) then represents the logarithmic transformation of the administrative fine level. In our dataset, an administrative fine was imposed in $62 \%$ of the cases in which the fining procedure was started. Some descriptive statistics on the level of administrative fines are given in Table 4. The average fine is significantly higher than the median, so its distribution is again skewed to the right.

\begin{tabular}{|l|l|l|l|l|l|}
\hline Variable & Count & Average & Median & Max & Min \\
\hline
\end{tabular}




\begin{tabular}{|l|l|l|l|l|l|}
\hline Amount (in €) & 399 & 3628 & 785 & 102915 & 62 \\
\hline
\end{tabular}

Table 4: Descriptive statistics for level of administrative fines

\subsection{Explanatory variables}

The signs of the variables serving as proxies for the degree of voluntary risk exposure (intent), gain and harm provide an indication of the type of objectives pursued by judges and administrations. Therefore, it is important to select the necessary proxies with care. We define a set of variables to measure the judge's perception with respect to the defendant's intentionality, with respect to the profits realized by violating the regulation and with respect to the level of (environmental) harm caused. Moreover, we add a set of control variables to account for the type of offender, contamination type, regional differences, etc. Note that we checked for multi-collinearity among the explanatory variables and that we eliminated all correlations which exceeded $50 \%$. Next, we discuss the proxies for intent, gain and harm for both the criminal and administrative track.

Firstly, in the criminal track, the perception on the degree of intentionality is measured by the dummy variable INTENT. This variable is deduced from the judge's written motivation statement (which is a mandatory complement for each verdict) and is equal to one if statements ${ }^{6}$ were made that the offense is considered to have been purposely committed. The variable REPEAT was also derived from the written verdict and is equal to one if the judge mentions that the violator was a repeat offender. Next, the dummy PREWARN equals one if the offense was reported by an administrative agency before being brought to court, which is a sign of warnings previous to trial. For the administrative cases, the variables INTENT and REPEAT are defined in an analogous way as for the criminal cases. The PREWARN variable is now equal to one if the administrative agency set up a proof of default document before the defendant was brought to court, which is again a sign of warnings previous to trial. Finally, we include the dummy TECHNICAL for the administrative cases only. This dummy is equal to one if the offense was not caused by a human action, but was due to some

\footnotetext{
${ }^{6}$ These statements include the use of the terms 'knowingly and willingly', 'sustained', 'intentionally', 'on purpose', 'purposely', or 'unwillingness'.
} 
mechanical/technical failure. This variable indicates that the extent of intentionality was probably rather low. Unfortunately, we could not include any measure of avoidance in our empirical estimation, because avoidance efforts by offenders is by definition hidden and unobserved.

Secondly, we derive the judge's perception of the profits made by violating the regulation from the written verdict. The dummy variable GAIN is equal to 1 if one of the following expressions was present in the judge's motivation of the verdict: 'pursuit of profit', 'economic profits', 'self-interest', 'financial profit' or 'economic stakes'. In addition, we define a variable LNFORFEIT, which represents the (logarithmically transformed) amount of illicit gains (in euro) that the public prosecutor requested to be removed. In the administrative enforcement track in Brussels-Capital Region, there is little or no information available to identify a gain component. Firstly, it is not possible for the administration to request for removal of illicit gains in administrative cases. In addition, the written motivations that accompany sanctioning decisions are much less elaborate in their description and none of the decisions in our dataset explicitly mentions profits as a motivation for imposing higher fines. One of the officers of the administrative enforcement agency in Brussels (BIM) explained us that: "Although economic profit or GAIN is one of the elements that is taken into account when determining the appropriate level of a particular fine, it is not always clear how to calculate the profits that violating persons/firms have made. However, there are specific regulations for which exact calculations of profits, or costs avoided, is possible. For example, in the regulation on transformers containing PCBs, the cost of removal of these transformers is taken into account." Moreover, Billiet (2008), a judge of the Brussels' administrative court of appeal, mentions that BIM seems to take the illegal profit into account when calculating the level of the fine for PCB-related cases.

Thirdly, for approximating the harm caused in the criminal track, we define the dummies NATURE, HEALTH and CIVIL PARTY. These are equal to one if (for at least one of the defendant's proven offenses) natural resources were affected, public health was affected or an affected third party was included in the case. Furthermore, the dummy variable DAMAGE is derived from the judge's motivation of the verdict and indicates his perception on the level of harm caused. DAMAGE equals 1 if the text mentions at least 
one of the terms 'damage', 'lack of respect', 'pollution' or 'contamination'. We also include a count variable for the number of proven offenses, which we call OFFENSES. Finally, we add the variable 'POSITIVE action' to indicate whether actions were undertaken by the defendant to mitigate the extent of environmental damages caused, or to reduce the level of the environmental risk in the 'no harm' case. To measure the extent of harm in the administrative track, we use the same variables as in the criminal track, except that NATURE is dropped, due to insufficient observations, as well as CIVIL PARTY, because it is not possible to present yourself as affected third party in administrative cases. We also include the variable ASBESTOS to analyze the administrative fining decisions. The dummy ASBESTOS indicates that the offense involved the toxic substance asbestos thus causing serious environmental risk as well as health risks. Therefore, this variable can be interpreted as a proxy for high risk behavior.

Finally, we include control variables for the type of offender which can be a legal entity (FIRM), an individual charged within his/her professional capacity (PROF), or an individual charged within his/her private capacity. We also control for contamination type through the inclusion of the three dummies: WASTE to indicate violations related to illegal waste disposal, NOISE for violations related to noise nuisance, SOIL-WATER for soil or water pollution offenses, and ODOR-AIR for violations that are related with odor or air pollution problems. Then, we control for cases related to AIRPLANE noise, because this is a quite specific and large group among the administrative enforcement cases. Finally we also include regional and year dummies to control for regional differences and variations over time.

\section{Estimation}

First, we briefly discuss the estimation method used and next we present the results from the estimations for the criminal and administrative environmental sanctioning processes in respectively Flanders and Brussels. 


\subsection{Estimation method}

We start by testing for differences in means between our two subsets - 'harm' versus 'no harm' - using the non-parametric Wilcoxon rank-sum test. We find significant differences between the means for the 'harm' and 'no harm' sanctioning decisions in the criminal as well as in the administrative sanctioning track. So, it is indeed better to estimate two separate regression models for the 'harm' (case 1) and 'no harm' (case 2) subsets.

We then estimate four regression models: two for each enforcement track and two for distinguishing between the 'harm' and 'no harm' cases. We estimate these models using ordinary least squares in which the level of the sanction is the dependent variable $F_{i}$. Further, the judicial perception on offender intentionality is denoted as $\alpha_{i}$, judge's perception on gains made by violating the regulation is denoted by $\Pi_{i}$ (this equals $C_{i}(0)-C_{i}\left(\alpha_{i}\right)$ in our theoretical analysis), judicial perception on the level of environmental harm is denoted by $h_{i}$ and the control variables are denoted as $X_{i}$. Formally, the OLS regression function can thus be written down as:

$$
F_{i}=C+\lambda * \alpha_{i}+\delta * \Pi_{i}+\phi^{*} h_{i}+\eta * X_{i}+u_{i}
$$

We also estimate a two-step regression model to evaluate the robustness of the OLS coefficients. We first estimate a probit model of the probability that a sanction is imposed, in which the error term $\varepsilon_{i}$ is assumed to follow a standard-normal distribution:

$$
\operatorname{Pr}\left(\text { Sanction }_{i}=1 \mid \alpha_{i}, \Pi_{i}, h_{i}, X_{i}\right)=\Phi\left[\varepsilon_{i}>-\left(C+\lambda * \alpha_{i}+\delta * \Pi_{i}+\phi^{*} h_{i}+\eta^{*} X_{i}\right)\right]
$$

Next, we estimate the level of the imposed sanction, using the Inverse Mills Ratio $\Lambda_{i}$ as a correction term for possible sample selection bias (Heckman 1979). In this equation, the coefficient for $\Lambda_{i}$ equals the covariance between the standard error of the probit regression model and the error of this linear specification:

$$
F_{i}=C+\lambda * \alpha_{i}+\delta * \Pi_{i}+\phi^{*} h_{i}+\eta^{*} X_{i}+\left(\rho^{*} \sigma_{\varepsilon} * \sigma_{v}\right) * \Lambda_{i}+v_{i}
$$

The results of the two-step estimation can be found in Appendix 2 . 


\subsection{Estimation results}

We start by discussing the empirical results of the criminal enforcement track, in which we separately analyze the cases where harm occurred and where no harm occurred. Next, we turn to the empirical results of the administrative enforcement track, in which 'harm' and 'no harm' cases are again separately analyzed.

\subsubsection{Criminal enforcement}

The estimation results for criminal enforcement of environmental offenses in Flanders are given in Table 5.

First we discuss the results for the 'harm' cases and subsequently turn to the 'no harm' cases. Looking at the proxies for intentionality in the 'harm' group, we find that REPEAT and PREWARN positively influence the level of the sanction. Next, we find that in cases where the economic benefits associated with the offense are regarded as an important element by the judge (GAIN) the sanction increases significantly. The requested FORFEITURE of illegal gains also has a significant impact. In terms of economic significance, it is important to bear in mind that LNFORFEIT is a continuous variable, whereas most of the other explanatory variables are discrete dummy variables. Furthermore, we see that harm is an important determinant of the probability of being sanctioned, as we expected. Offenses that had negative health effects (HEALTH) are sanctioned significantly more severe. Also, sanction levels increase significantly for high DAMAGE offenses, for cases where CIVIL PARTIES are involved and for a higher number of OFFENSES committed (for economic significance keep in mind that OFFENSES is a count variable rather than a dummy variable). Offenders who reacted quickly to control and clean up the environmental harm (POSITIVE) incur a significantly lower sanction.

Looking at the control variables, we see that firms (FIRM) are sanctioned significantly more severely than offenders who committed the offense in their private capacity. In contrast, individual offenders in official capacity (PROF) incur significantly lower sanctions. Next, we observe that WASTE related offenses lead to higher sanction levels. 
Finally, offenders in the regions of KORTRIJK and BRUGES can expect to incur lower sanctions.

In Appendix 2, Table 9 shows the results of the two-step regression model for criminal 'harm' cases, as described in section 4.1. In general, the coefficients that we found using the OLS regression are quite robust. What we find is that some of our significant variables rather have an impact on the probability of sanction (REPEAT, HEALTH, WASTE), while others lead to higher sanction levels once the decision to impose a sanction has been taken (LNFORFEIT, DAMAGE, CIVIL PARTY, OFFENSES, PROF, FIRM, BRUGES, KORTRIJK).

We now turn to the regression results for the criminal 'no harm' cases. Looking at the impact of intentionality variables, we again see that REPEAT offenders and offenders who received 'warnings' prior to being brought to trial (PREWARN) can expect significantly higher sanction levels. Further, we find that the judicial perception on the violations' profitability (GAIN) positively influences the sanction level. POSITIVE actions taken after the offense to limit the environmental hazards leads to a sanction decrease. Finally, we see that PROF offenders incur lower sanctions and that in the jurisdiction of BRUGES sanctions are also significantly lower.

\begin{tabular}{|c|c|c|}
\hline & HARM & NO HARM \\
\hline Dep Var & \#obs & \#obs \\
\hline LN(CRISANC) & 1048 & 265 \\
\hline Variables & Coeff. (Std.Err.) & Coeff. (Std.Err.) \\
\hline ONE & $4,453(0,355) *$ & $5,410(0,620) *$ \\
\hline INTENT & $0,280(0,284)$ & $-0,378(0,547)$ \\
\hline REPEAT & $0,915(0,254) *$ & $1,991(0,565)^{*}$ \\
\hline PREWARN & $1,645(0,229)^{*}$ & $1,893(0,562) *$ \\
\hline GAIN & $1,730(0,269) *$ & $2,565(0,565)^{*}$ \\
\hline LNFORFEIT & $0,242(0,038) *$ & $0,117(0,075)$ \\
\hline HEALTH & $1,361(0,381)^{*}$ & \\
\hline NATURE & $-0,653(0,439)$ & \\
\hline DAMAGE & $0,523(0,212) * *$ & $0,708(0,590)$ \\
\hline CIVIL PARTY & $0,760(0,241) *$ & \\
\hline OFFENSES & $0,101(0,049) * *$ & $-0,106(0,111)$ \\
\hline POSITIVE & $-1,412(0,238)^{*}$ & $-1,264(0,502) * *$ \\
\hline WASTE & $0,604(0,269)^{* * *}$ & \\
\hline
\end{tabular}




\begin{tabular}{|c|c|c|}
\hline NOISE & & $-0,201(0,500)$ \\
\hline SOILWATER & $-0,527(0,297)$ & $0,083(0,580)$ \\
\hline ODORAIR & $0,431(0,360)$ & - \\
\hline PROF & $-0,467(0,237)^{* * *}$ & $-1,332(0,448) *$ \\
\hline FIRM & $0,916(0,295)^{*}$ & $-0,226(0,545)$ \\
\hline GENT & $-0,158(0,232)$ & $0,414(0,548)$ \\
\hline OUDENAARDE & $-0,062(0,366)$ & $-1,488(1,724)$ \\
\hline KORTRIJK & $-1,185(0,404) *$ & $-0,354(0,640)$ \\
\hline BRUGES & $-0,994(0,390) * *$ & $-2,824(0,638) *$ \\
\hline WESTHOEK & $0,148(0,356)$ & $-0,699(0,673)$ \\
\hline Y04 & $-0,218(0,279)$ & $-0,723(0,508)$ \\
\hline Y05 & $0,458(0,260)$ & $0,520(0,569)$ \\
\hline Y06 & $-0,009(0,257)$ & $-0,207(0,545)$ \\
\hline $\operatorname{adj} . R^{2}$ & 0,300 & 0,373 \\
\hline
\end{tabular}

Table 5: Estimation of criminal sanction level for 'harm' and 'no harm' cases (** indicates statistical significance at $1 \%$ level, * indicates statistical significance at $5 \%$ level)

Looking at the results of the two-step regression in Table 102 of Appendix 2, we see that the significant effects for the variables REPEAT, PREWARN, POSITIVE and PROF are all mainly due to an increase or decrease in the sanction probability, rather than in the sanction level.

\subsubsection{Administrative enforcement}

We now address the regression results for the administrative enforcement track, which are outlined in Table 6.

\begin{tabular}{|l|r|r|}
\hline & \multicolumn{1}{|c|}{ HARM } & \multicolumn{1}{c|}{ NO HARM } \\
\hline Dep Var & \multicolumn{1}{|c|}{ \#obs } & \multicolumn{1}{c|}{ \#obs } \\
\hline LN(ADMSANC) & \multicolumn{1}{|c|}{276} & \multicolumn{1}{c|}{334} \\
\hline Variables & Coeff. (Std.Err.) & Coeff. (Std.Err.) \\
\hline ONE & $\mathbf{1 , 3 7 8 ( \mathbf { 0 , 7 0 0 } ) * *}$ & $\mathbf{3 , 4 5 4}(\mathbf{0 , 7 2 0}) *$ \\
INTENT & $-1,301(0,682)$ & $-0,737(0,474)$ \\
REPEAT & $\mathbf{1 , 7 4 9 ( \mathbf { 0 , 3 9 3 } ) *}$ & $0,548(0,486)$ \\
PREWARN & $0,425(0,422)$ & $\mathbf{0 , 7 4 7}(\mathbf{0 , 3 3 0}) * *$ \\
TECHNICAL & $\mathbf{- 1 , 0 3 1 ( \mathbf { 0 , 4 5 7 } ) * *}$ & - \\
HEALTH & $\mathbf{1 , 8 0 3 ( \mathbf { 0 , 3 8 8 } ) *}$ & - \\
ASBESTOS & & $\mathbf{1 , 1 4 3 ( \mathbf { 0 , 4 9 0 } ) * *}$ \\
OFFENSES & $\mathbf{0 , 1 0 9 ( \mathbf { 0 , 0 2 7 } ) *}$ & $0,054(0,047)$ \\
POSITIVE & $\mathbf{- 1 , 7 9 2 ( \mathbf { 0 , 2 9 9 } ) *}$ & $\mathbf{- 3 , 3 1 2}(\mathbf{0 , 3 0 9}) *$
\end{tabular}




\begin{tabular}{|l|r|r|} 
WASTE & - & $\mathbf{0 , 8 2 7}(\mathbf{0 , 3 6 2})^{* *}$ \\
SOILWATER & $-0,311(0,471)$ & - \\
ODORAIR & $0,494(0,520)$ & $-0,280(0,590)$ \\
PROF & $\mathbf{2 , 0 7 6 ( \mathbf { 0 , 6 4 6 } ) ^ { * }}$ & $-0,036(0,701)$ \\
FIRM & $\mathbf{2 , 4 0 5 ( \mathbf { 0 , 6 3 1 } ) *}$ & $0,573(0,673)$ \\
AIRPLANE & $\mathbf{1 , 8 0 9 ( \mathbf { 0 , 4 8 3 } ) *}$ & - \\
Y05 & $0,179(0,425)$ & $\mathbf{0 , 7 6 9 ( \mathbf { 0 , 3 4 9 } ) * *}$ \\
Y06 & $0,070(0,432)$ & $\mathbf{0 , 8 5 4}(\mathbf{0 , 3 8 2}) * *$ \\
\hline adj R & 0,557 & 0,351 \\
\hline
\end{tabular}

Table 6: Estimation of administrative sanction level for the 'harm' and 'no harm' cases (** indicates statistical significance at $1 \%$ level, * indicates statistical significance at $5 \%$ level)

We first discuss the empirical results for 'harm' cases. Again, we find that REPEAT offenders incur significantly higher sanctions. We also see that offenses due to mechanical/technical failures (TECHNICAL) are sanctioned significantly less severely. Among the variables measuring harm, we find that negative HEALTH impacts lead to a sanction increase, that the sanction augments for each additional offense and that sanctions decrease significantly with POSITIVE actions. Finally, for the control variables we find that FIRM and PROF receive higher fines, while in the specific cases where violators are AIRPLANE companies, i.e. noise related violations, the average sanction is also significantly higher.

The results of the two-step regression are shown in Table 13 of Appendix 2. The estimated OLS coefficients are again quite robust. The main difference is that the PREWARN variable has a significantly positive effect on the sanction level here (after the sanctioning decision has been taken). The significant OLS coefficients for TECHNICAL, HEALTH and POSITIVE can mainly be attributed to changes in the sanction probability, rather than changes in the sanction amount. The significant coefficient for AIRPLANE, in contrast, comes mainly from higher sanction level, rather than a higher sanction probability. The positive effect for the variable OFFENSES seems to be a combination of a higher probability and a higher level.

For the administrative 'no harm' cases, we see that fines increase with the violation being documented previous to the case proceeding to court (PREWARN). We also observe that fines are higher in more 'risky' cases (ASBESTOS) and that they are lower 
if the offender took POSITIVE actions. Finally, expected fines turn out to be significantly higher for WASTE related cases, for the year 2005 and for the year 2006.

The results for the two-step regression are shown in Table 14 of Appendix 2. All the significant coefficients from the OLS regression can be explained by an increase in the sanction probability, rather than in the sanction level. However, the sanction level is higher for REPEAT offenders and for violators that are accused of committing multiple OFFENSES.

\section{Discussion of the results}

Based on the preceding empirical analysis, we can now comment on the impact of the degree of intentionality on the stringency of the expected sanction in both the criminal and administrative enforcement track. Our results also provide evidence of the objectives pursued by the enforcing authorities. In order to facilitate the discussion, we summarize the results for criminal enforcement cases in Table 7 and for administrative enforcement in Table 8. In each group, we first look at the evidence for the harm cases and next we analyze the 'no harm' cases.

For the criminal enforcement cases where environmental harm occurred, we find mixed evidence for the judges objective functions. The increasing expected sanctions associated with the gain related factors (GAIN and FORFEIT) point toward a desire to maximize compliance, while the increasing sanctions associated with the harm related factors (HEALTH, DAMAGE, CIVIL PARTY, OFFENSES and POSITIVE) point to a judicial objective function that includes social welfare maximization. Thus, judicial objectives can be described as a combination of both social welfare maximization and compliance maximization. This corresponds to the findings of Blondiau and Rousseau (2010) who also find evidence of both objectives in the behavior of criminal judges in Flanders.

With respect to the effect of intentionality, we find quite strong empirical evidence that criminal sanctions increase with intentionality. Note that this result holds even after controlling for the (judicial perception) on the level of harm and gain associated with this offense. Thus, in analogy with Shavell (1985), the effect of intent on increasing penalties 
must be correlated with the offender's avoidance effort. We could not control for this effect in our empirical analysis, but we have shown in our theoretical part that it is difficult to explain an increase in optimal sanctions through the avoidance effect alone. Thus, it seems difficult to explain that judges, though consistent with legal theory, systematically impose higher sanctions for intentional offenders after controlling for the level of harm and gain.

We now discuss the results for the 'no harm' cases. We again find evidence of a combination of objectives in judicial decision making. Social welfare maximization is observable in the finding that expected sanctions decrease with lower harm, or with lower levels of risk imposed on society (POSITIVE). Evidence for compliance maximization can be found in the positive influence of profit-making (GAIN) on the expected sanction level. The fact that intentional violations (REPEAT and PREWARN) lead to higher expected sanctions is consistent with our theoretical analysis here, because expected harm increases with intentionality.

\begin{tabular}{|c|c|c|c|c|}
\hline \multicolumn{2}{|c|}{$\begin{array}{l}\text { CRIMINAL } \\
\text { ENFORCEMENT }\end{array}$} & $\begin{array}{l}\text { Voluntary risk } \\
\text { exposure (intent) }\end{array}$ & Gain & Harm \\
\hline \multirow{2}{*}{ Theory: HARM } & $\begin{array}{l}\text { Max social } \\
\text { welfare }\end{array}$ & $?$ & Constant & Increase \\
\hline & $\begin{array}{c}\text { Max } \\
\text { compliance }\end{array}$ & $?$ & Increase & Constant \\
\hline $\begin{array}{l}\text { Empirics: } \\
\text { HARM }\end{array}$ & $\begin{array}{l}\text { Sanction } \\
\text { level }\end{array}$ & $\begin{array}{c}\text { REPEAT + } \\
\text { PREWARN + }\end{array}$ & $\begin{array}{c}\text { GAIN + } \\
\text { FORFEIT + }\end{array}$ & $\begin{array}{c}\text { HEALTH + } \\
\text { DAMAGE + } \\
\text { CIVIL PARTY + } \\
\text { OFFENSES + } \\
\text { POSITIVE - }\end{array}$ \\
\hline \multirow{2}{*}{$\begin{array}{l}\text { Theory: } \\
\text { NO HARM }\end{array}$} & $\begin{array}{l}\text { Max social } \\
\text { welfare }\end{array}$ & Increase & Constant & Increase \\
\hline & $\begin{array}{l}\text { Max } \\
\text { compliance }\end{array}$ & Increase & Increase & Constant \\
\hline $\begin{array}{l}\text { Empirics: } \\
\text { NO HARM }\end{array}$ & $\begin{array}{l}\text { Sanction } \\
\text { level }\end{array}$ & $\begin{array}{c}\text { REPEAT + } \\
\text { PREWARN + }\end{array}$ & GAIN + & POSITIVE - \\
\hline
\end{tabular}

Table 7: Overview of empirical results for criminal enforcement 
Next, we turn to the results for administrative enforcement. We start by discussing the 'harm' cases. We find that expected administrative fines are increasing with harm (HEALTH, OFFENSES and POSITIVE). Thus, we find positive evidence of social welfare maximization. In contrast, we find only indirect evidence of compliance maximization, mainly because of the reluctance of the administrative authority to include references to gain in the written motivations (as discussed in section 3.3). However, we also see that in practice sanctions are increasing with intentionality (REPEAT and TECHNICAL). This indicates that the administrative enforcement agency does not limit itself to imposing compensatory damages for intentional offenders. According to Cooter (1984) this shows that judges do not use sanctions as 'prices', but rather as real 'sanctions'. This also indicates that judges' objectives are not limited to maximization of welfare and again point in the direction of mixed objectives for the administrative enforcement officers.

\begin{tabular}{|c|c|c|c|c|}
\hline \multicolumn{2}{|c|}{$\begin{array}{l}\text { ADMINISTRATIVE } \\
\text { ENFORCEMENT }\end{array}$} & $\begin{array}{c}\text { Voluntary risk } \\
\text { exposure (intent) }\end{array}$ & Gain & Harm \\
\hline \multirow[t]{2}{*}{$\begin{array}{l}\text { Theory: } \\
\text { HARM }\end{array}$} & $\begin{array}{l}\text { Max social } \\
\text { welfare }\end{array}$ & $?$ & Constant & Increase \\
\hline & Max compliance & $?$ & Increase & Constant \\
\hline $\begin{array}{l}\text { Empirics: } \\
\text { HARM }\end{array}$ & Sanction level & $\begin{array}{c}\text { REPEAT + } \\
\text { TECHNICAL - }\end{array}$ & $\mathrm{X}$ & $\begin{array}{c}\text { HEALTH + } \\
\text { OFFENSES + } \\
\text { POSITIVE - }\end{array}$ \\
\hline \multirow{2}{*}{$\begin{array}{l}\text { Theory: } \\
\text { NO HARM }\end{array}$} & $\begin{array}{l}\text { Max social } \\
\text { welfare }\end{array}$ & Increase & Constant & Increase \\
\hline & Max compliance & Increase & Increase & Constant \\
\hline $\begin{array}{l}\text { Empirics: } \\
\text { NO HARM }\end{array}$ & Sanction level & PREWARN + & $\mathrm{X}$ & $\begin{array}{c}\text { ASBESTOS + } \\
\text { POSITIVE - }\end{array}$ \\
\hline
\end{tabular}

Table 8: Overview of empirical results for administrative enforcement 
For the 'no harm' cases, the evidence for social welfare maximization is straightforward. We find that the higher the level of risk imposed by a certain offense (ASBESTOS and POSITIVE), the higher the expected fine level. Due to the lack of information on gain related factors, we can again only give indirect evidence for the administration's compliance objectives. The fact that administrative fines are increasing with intentionality (PREWARN) is consistent with our theoretical analysis here. But it cannot be used to distinguish between social welfare or compliance maximization objectives.

\section{Conclusion}

In the theoretical analysis, we tried to answer the question whether intentional violators should be punished more harshly than accidental violators under different enforcement objectives (i.e. welfare maximization and compliance maximization). We showed that sanctions should be higher under both objectives if no actual harm occurred but risky actions were intentionally taken by violators. In case actual harm occurred, we cannot generally sign the effect of intentionality on the optimal sanction level under either of the objective functions. This is mainly because of the counter-balancing effects that intentionality and avoidance efforts have on the prosecution probability. Looking at the sanctioning decisions by courts of first instance in Flanders and the environmental administration in Brussels, we tested whether intentional violators are punished more harshly than accidental violators in practice. The empirical evidence in both criminal and administrative sanctions clearly showed that sanctions for environmental offenses are increasing in the level of intent. This seems to indicate that intentionality is indeed an important motivating factor to impose higher sanctions in practice.

The analysis also provided evidence on the objectives pursued by enforcing authorities when sanctioning environmental offenders. Since the probability as well as the level of sanctions increases with the level of environmental harm, decisions made by courts and administration both point to social welfare maximizing behavior. The fact that the probability and level of sanctions increases with the illegal gain obtained from environmental violations indicates a desire by the enforcing authorities to maximize compliance. 
Thus, the empirical evidence clearly indicates that enforcing authorities often pursue multiple objectives. However, theoretical models are often limited to one particular objective function which makes their resulting conclusions less relevant in practice. It seems important to find ways of dealing with combinations of objectives when analyzing optimal sanctions. Explicitly taking these combinations into account might also help in the communication between economic scholars, legal scholars and enforcing authorities. Conflicting opinions and results might simply be caused by an incorrect or partial specification of the objective functions. 


\section{Bibliography}

Biliet, C.M. (2008). Bestuurlijke sanctionering van milieurecht. Intersentia.

Billiet, C.M., Rousseau, S., Balcaen, A., Meeus, R., Styns, K., De Meyer, G., Vander Beken, T. en L. Lavrysen (2009). Milieurechtshandhaving: een databestand voor onderzoek naar de penale en bestuurlijke sanctioneringspraktijk. Tijdschrift voor Milieurecht 18 (2): 128-150.

Blondiau, T. and S. Rousseau (2010). The impact of the judicial objective function on the enforcement of environmental standards. Journal of Regulatory Economics 37(2): 196214

Bowles, R., Faure, M. and N. Garoupa (2005). Forfeiture of illegal gain: An economic perspective. Oxford Journal of Legal Studies 25(2): 275-295.

Cohen, M. (1999). Monitoring and enforcement of environmental policy. In: Tietenberg, T. and Folmer, H. (eds.), International yearbook of environmental and resource economics, Volume III, Edward Elgar Publishers.

Cooter, R. (1984). Prices and sanctions. Columbia Law Review 84: 1523-1560.

DEP (2002). Guidance for calculation of civil penalties for willfulness. Department of Environmental Protection

Firestone, J. (2002). Agency governance and enforcement: The influence of mission on environmental decisionmaking. Journal of Policy Analysis and Management 21: 409426.

Garoupa, N. and M. Obidzinski (2006). The Scope of Punishment: An Economic Theory of Harm-Based vs. Act-Based Sanctions. CEPR discussion paper

Harrington, W. (1988). Enforcement leverage when penalties are restricted. Journal of Public Economics 37: 29-53.

Heckman, J. (1979). Sample selection bias as a specification error. Econometrica 47: 153-161. 
Heyes, A. and S. Kapur (2009). Enforcement missions: targets vs. budgets. Journal of Environmental Economics and Management 58: 129-140.

Innes, R. (2004). Enforcement costs, optimal sanctions and the choice between ex-post liabilitiy and ex-ante regulation. International Review of Law and Economics 24(1): $29-48$

Langlais, E. (2008). Detection avoidance and deterrence: some parodoxical arithmetic. Journal of Public Economic Theory 10(3): 371-382

Malik, A. (1990). Avoidance, screening and optimum enforcement. RAND Journal of Economics 21: 341-353

Polinsky, A.M. and S. Shavell. (1992). Enforcement costs and the optimal magnitude and probability of fines. Journal of Law and Economics 35: 133-148

Polinsky, A.M. and S. Shavell. (1994). Should liability be based on the harm to the victim or the gain to the injurer? Journal of Law, Economics and Organization 10: 427437

Polinsky, A.M. and S. Shavell. (2000). The economic theory of public law enforcement. Journal of Economic Literature 38: 45-67

Rousseau, S. (2009). Empirical analysis of sanctions for environmental offenses. International Review of Environmental and Resource Economics 3: 161-194.

Sanchirico, C. (2006). Detection avoidance. New York University Law Review 81: 13311399

Shavell, S. (1985). Criminal law and the optimal use of nonmonetary sanctions as a deterrent. Columbia Law Review 85: 1232-1262.

Shavell, S. (1993). The optimal structure of law enforcement. Journal of Law and Economics 36(1): 255-287.

Van den Wyngaert (2006). Strafrecht, strafprocesrecht \& internationaal strafrecht. Maklu - Antwerpen/Apeldoorn. 1314p.

Wittman, D. (1984). Liability for harm or restitution for benefit? Journal of Legal Studies 13(1): 57-80. 
Wittman, D. (1985). Should compensation be based on costs or benefits? International Review of Law and Economics 5(2): 173-185. 


\section{Appendix 1}

We compare differences in maximum fines with differences in maximum imprisonment sentences for different regulations, to deduce the implicit monetary value that the legislator assigns to prison sentences. We derive monthly monetary values to compare different regulations. The results are shown in the table below for different regulations included in our database (Billiet et al. 2009).

\begin{tabular}{|l|c|c|c|c|}
\hline Act (Year) & $\begin{array}{c}\text { Maximum } \\
\text { fine natural } \\
\text { body (1) }\end{array}$ & $\begin{array}{c}\text { Maximum } \\
\text { fine legal } \\
\text { body (2) }\end{array}$ & $\begin{array}{c}\text { Implied monetary } \\
\text { value of prison } \\
\text { sentence (3)=(2)-(1) }\end{array}$ & $\begin{array}{c}\text { Implied monetary } \\
\text { value of monthly } \\
\text { prison sentence } \\
(4)=(3) / \# \text { months }\end{array}$ \\
\hline $\begin{array}{l}\text { Surface Water } \\
\text { Decree (1971) }\end{array}$ & $€ 27500$ & $€ 66000$ & 6 months $=€ 38500$ & $€ 6417$ \\
\hline $\begin{array}{l}\text { Noise Decree } \\
(1973)\end{array}$ & $€ 27500$ & $€ 66000$ & 6 months $=€ 38500$ & $€ 6417$ \\
\hline $\begin{array}{l}\text { Waste Decree } \\
(1981)\end{array}$ & $€ 55000000$ & $€ 110000000$ & 5 years $=€ 55000000$ & $€ 916667$ \\
\hline $\begin{array}{l}\text { Groundwater } \\
\text { Decree (1984) }\end{array}$ & $€ 660000$ & $€ 55000$ & 5 years $=€ 605000$ & $€ 10083$ \\
\hline $\begin{array}{l}\text { Environmental } \\
\text { Permit Decree } \\
(1985)\end{array}$ & $€ 550000$ & $€ 1100000$ & 1 year $=€ 550000$ & $€ 45833$ \\
\hline $\begin{array}{l}\text { Fertilizer } \\
\text { Decree (1991) }\end{array}$ & $€ 412500$ & $€ 825000$ & 6 months $=€ 412500$ & $€ 68750$ \\
& $€ 550000$ & $€ 1100000$ & 1 year $=€ 550000$ & $€ 45833$ \\
\hline $\begin{array}{l}\text { Soil Clean-up } \\
\text { Decree (1995) }\end{array}$ & $€ 55000000$ & $€ 110000000$ & 5 years $=€ 55000000$ & $€ 916667$ \\
\hline
\end{tabular}

The monetary value of a monthly prison sentence decreases with the length of the total prison sentence imposed. The additional deterrence effect of an effective imprisonment sentence is likely to be the strongest for the first months of a prison sentence and to marginally decrease for an additional month in case of a sentence of a longer duration. This logic is also apparent in the table above in the sentences for violation of the Fertilizer Decree. Thus, we estimated the following function to assign a monetary value to a marginal increase in the prison sentence: $\operatorname{MarMonE} q($ month $)=100.000^{0.497}$. 


\section{$\underline{\text { Appendix } 2}$}

Here we define a variable PROBCRIM equal to one if the judge imposed an effective sanction on the defendant and equal to zero if the verdict was postponed. The variable PROBADM equals one if an administrative fine was imposed and is zero otherwise.

\begin{tabular}{|c|c|c|c|}
\hline \multirow[b]{4}{*}{ Variables } & \multirow{2}{*}{$\frac{\text { PROBIT }}{\text { Dep Var \#obs }}$} & \multicolumn{2}{|l|}{ SELECTION } \\
\hline & & Dep Var & \#obs \\
\hline & PROBCRIM - 1048 & LNCRISANC & 920 \\
\hline & Coeff. (Std.Err.) & \multicolumn{2}{|c|}{ Coeff. in selection group (Std.Err) } \\
\hline ONE & $0,938(0,230)^{*}$ & & $5,496(0,487) *$ \\
\hline INTENT & $0,047(0,189)$ & & $0,292(0,242)$ \\
\hline REPEAT & $0,767(0,231)^{*}$ & & $0,453(0,358)$ \\
\hline PREWARN & $0,714(0,198) *$ & & $1,181(0,338) *$ \\
\hline GAIN & $0,601(0,222) *$ & & $1,424(0,322) *$ \\
\hline LNFORFEIT & $-0,014(0,026)$ & & $0,231(0,033) *$ \\
\hline HEALTH & $0,904(0,366) * *$ & & $0,770(0,464)$ \\
\hline NATURE & $-0,492(0,269)$ & & $-0,196(0,439)$ \\
\hline DAMAGE & $0,179(0,143)$ & & $0,439(0,194) *$ \\
\hline CIVIL PARTY & $0,296(0,169)$ & & $0,607(0,237)^{* *}$ \\
\hline OFFENSES & $0,000(0,028)$ & & $0,151(0,048) *$ \\
\hline POSITIVE & $-0,392(0,137)^{*}$ & & $-1,216(0,275)^{*}$ \\
\hline WASTE & $0,503(0,167) *$ & & $0,104(0,324)$ \\
\hline SOILWATER & $-0,021(0,182)$ & & $-0,469(0,261)$ \\
\hline ODORAIR & $0,301(0,256)$ & & $0,064(0,334)$ \\
\hline PROFESSIONAL & $-0,123(0,149)$ & & $-0,444(0,209) * *$ \\
\hline FIRM & $0,252(0,193)$ & & $0,796(0,275) *$ \\
\hline GENT & $-0,085(0,149)$ & & $-0,179(0,200)$ \\
\hline OUDENAARDE & $-0,141(0,226)$ & & $0,072(0,321)$ \\
\hline KORTRIJK & $-0,009(0,241)$ & & $-1,329(0,351)^{*}$ \\
\hline BRUGES & $-0,117(0,239)$ & & $-1,172(0,347) *$ \\
\hline WESTHOEK & $-0,167(0,223)$ & & $0,286(0,313)$ \\
\hline Y04 & $-0,391(0,180) * *$ & & $0,134(0,288)$ \\
\hline Y05 & $-0,093(0,178)$ & & $0,455(0,223)^{* *}$ \\
\hline Y06 & $-0,428(0,169) * *$ & & $0,275(0,281)$ \\
\hline LAMBDA & & & $-0,106(1,229)$ \\
\hline $\begin{array}{l}\text { Correct \% } \\
\text { (Benchmark) }\end{array}$ & $\begin{array}{r}69,37 \% \\
(88 \%) \\
\end{array}$ & Adj $R^{2}$ & 0,320 \\
\hline Correct $1 \%$ & $69,13 \%$ & & \\
\hline Correct $0 \%$ & $71,09 \%$ & & \\
\hline
\end{tabular}

Table 9 Two-step regression model for criminal 'harm' cases, using Heckman's correction for sample selection (** indicates statistical significance at $1 \%$ level, * at $5 \%$ level) 


\begin{tabular}{|c|c|c|c|}
\hline \multirow[b]{4}{*}{ Variables } & \multirow{2}{*}{$\begin{array}{l}\text { PROBIT } \\
\text { Dep Var \#obs }\end{array}$} & \multicolumn{2}{|l|}{ SELECTION } \\
\hline & & \multicolumn{2}{|l|}{ Dep Var } \\
\hline & PROBCRIM - 265 & LNCRISANC & 196 \\
\hline & Coeff. (Std.Err.) & \multicolumn{2}{|c|}{ Coeff. in selection group (Std.Err.) } \\
\hline ONE & $1,530(0,357)^{*}$ & & $6,829(0,559) *$ \\
\hline INTENT & $0,390(0,334)$ & & $-0,743(0,588)$ \\
\hline REPEAT & $1,513(0,473)^{*}$ & & $1,079(0,973)$ \\
\hline PREWARN & $1,050(0,407) * *$ & & $1,040(0,794)$ \\
\hline GAIN & & & $1,594(0,442) *$ \\
\hline LNFORFEIT & $-0,021(0,040)$ & & $0,130(0,096)$ \\
\hline DAMAGE & $0,114(0,365)$ & & $0,660(0,572)$ \\
\hline POSITIVE & $-1,012(0,283) *$ & & $-0,737(0,799)$ \\
\hline OFFENSES & $0,054(0,063)$ & & $-0,144(0,122)$ \\
\hline NOISE & $0,184(0,324)$ & & $-0,667(0,466)$ \\
\hline SOILWATER & $-0,343(0,299)$ & & $-0,056(0,629)$ \\
\hline PROFESSIONAL & $-0,692(0,261) *$ & & $-0,810(0,591)$ \\
\hline FIRM & $-0,224(0,318)$ & & $0,126(0,526)$ \\
\hline GENT & $-0,438(0,325)$ & & $0,856(0,569)$ \\
\hline OUDENAARDE & $-1,557(0,893)$ & & $0,558(1,903)$ \\
\hline KORTRIJK & $-0,082(0,395)$ & & $-1,064(0,580)$ \\
\hline BRUGES & $-1,333(0,343) *$ & & $-2,732(1,095)^{* *}$ \\
\hline WESTHOEK & $-1,175(0,348)^{*}$ & & $0,572(1,051)$ \\
\hline Y04 & $-0,083(0,289)$ & & $-0,613(0,504)$ \\
\hline Y05 & $0,119(0,316)$ & & $0,889(0,550)$ \\
\hline Y06 & $-0,022(0,309)$ & & $0,889(0,527)$ \\
\hline LAMBDA & & & $-1,555(1,199)$ \\
\hline $\begin{array}{l}\text { Correct \% } \\
\text { (Benchmark) }\end{array}$ & $\begin{array}{l}83,6 \% \\
(74 \%)\end{array}$ & Adj. $\mathrm{R}^{2}$ & 0,361 \\
\hline Correct $1 \%$ & $84,2 \%$ & & \\
\hline Correct $0 \%$ & $78,3 \%$ & & \\
\hline
\end{tabular}

Table 102 Two-step regression model for criminal 'no harm' cases, using Heckman's correction for sample selection (** indicates statistical significance at $1 \%$ level, * significance at $5 \%$ level)

\begin{tabular}{|c|c|c|c|}
\hline & PROBIT & \multicolumn{2}{|l|}{ SELECTION } \\
\hline & Dep Var \#obs & Dep var & \#obs \\
\hline & PROBADM - 276 & LNADMSANC & 216 \\
\hline Variables & Coeff. (Std.Err.) & \multicolumn{2}{|c|}{$\begin{array}{l}\text { Coeff. in selection group } \\
\text { (Std.Err.) }\end{array}$} \\
\hline ONE & $-0,554(0,501)$ & \multicolumn{2}{|c|}{$2,905(0,599) * *$} \\
\hline INTENT & $-0,853(0,435)$ & \multicolumn{2}{|c|}{$-0,313(0,477)$} \\
\hline REPEAT & $0,921(0,412) *$ & \multicolumn{2}{|c|}{$1,136(0,255)^{* *}$} \\
\hline PREWARN & $-0,152(0,292)$ & \multicolumn{2}{|c|}{$0,747(0,267) * *$} \\
\hline TECHNICAL & $-0,657(0,327) *$ & \multicolumn{2}{|c|}{$-0,006(0,315)$} \\
\hline
\end{tabular}




\begin{tabular}{|c|c|c|c|}
\hline HEALTH & $1,407(0,301)^{* *}$ & & $0,076(0,353)$ \\
\hline OFFENSES & $0,037(0,024)$ & & $0,101(0,064)$ \\
\hline POSITIVE & $-1,387(0,272)^{* *}$ & & $-0,303(0,302)$ \\
\hline SOILWATER & $-0,109(0,326)$ & & $0,307(0,306)$ \\
\hline ODORAIR & $0,303(0,374)$ & & $-0,746(0,338) *$ \\
\hline PROFESSIONAL & $1,194(0,471)^{*}$ & & $1,276(0,480)^{* *}$ \\
\hline FIRM & $1,088(0,452)^{*}$ & & $1,714(0,479) * *$ \\
\hline AIRPLANE & $0,590(0,462)$ & & $1,588(0,292)^{* *}$ \\
\hline Y05 & $0,154(0,305)$ & & $0,286(0,263)$ \\
\hline Y06 & $0,208(0,320)$ & & $0,147(0,267)$ \\
\hline LAMBDA & & & $1,217(0,466)^{* *}$ \\
\hline $\begin{array}{l}\text { Correct \% } \\
\text { (Benchmark) }\end{array}$ & $\begin{array}{l}85,5 \% \\
(78 \%)\end{array}$ & Adj $R^{2}$ & \begin{tabular}{l|l} 
& 0,686
\end{tabular} \\
\hline Correct 1\% & $86,6 \%$ & & \\
\hline Correct $0 \%$ & $81,7 \%$ & & \\
\hline
\end{tabular}

Table 13 Two-step regression model for administrative 'harm' cases, using Heckman's correction for sample selection (** indicates statistical significance at $1 \%$ level, * significance at $5 \%$ level)

\begin{tabular}{|c|c|c|c|}
\hline & PROBIT & \multicolumn{2}{|l|}{ SELECTION } \\
\hline \multirow[b]{3}{*}{ Variables } & Dep Var \#Obs & Dep Var & \#Obs \\
\hline & PROBADM - 334 & LNADMSANC & 183 \\
\hline & Coeff. (Std.Err.) & \multicolumn{2}{|c|}{ Coeff. in selection group (Std.Err.) } \\
\hline ONE & $-0,004(0,415)$ & & $5,926(0,351) *$ \\
\hline INTENT & $-0,519(0,263) * *$ & & $0,111(0,188)$ \\
\hline REPEAT & $0,095(0,269)$ & & $0,531(0,112) *$ \\
\hline PREWARN & $0,342(0,177)$ & & $0,156(0,126)$ \\
\hline ASBESTOS & $0,702(0,281)^{* *}$ & & $-0,098(0,222)$ \\
\hline POSITIVE & $-1,505(0,166)^{*}$ & & $-0,060(0,479)$ \\
\hline OFFENSES & $0,015(0,023)$ & & $0,052(0,015)^{*}$ \\
\hline WASTE & $0,421(0,194)^{* *}$ & & $0,106(0,155)$ \\
\hline ODORAIR & $-0,088(0,352)$ & & $-0,111(0,139)$ \\
\hline PROFESSIONAL & $-0,017(0,406)$ & & $0,207(0,189)$ \\
\hline FIRM & $0,310(0,393)$ & & $0,243(0,204)$ \\
\hline Y05 & $0,437(0,191)^{* * *}$ & & $-0,003(0,156)$ \\
\hline Y06 & $0,481(0,209) * *$ & & $0,043(0,168)$ \\
\hline LAMBDA & & & $0,221(0,386)$ \\
\hline $\begin{array}{l}\text { Correct \% } \\
\text { (Benchmark) }\end{array}$ & $\begin{array}{l}78,1 \% \\
(55 \%)\end{array}$ & Adj $R^{2}$ & \\
\hline Correct $1 \%$ & $79,8 \%$ & & \\
\hline Correct $0 \%$ & $76,2 \%$ & & \\
\hline
\end{tabular}

Table 11 Two-step regression model for administrative 'no harm' cases, using Heckman's correction for sample selection (** indicates statistical significance at $1 \%$ level, * significance at $5 \%$ level) 